\title{
The Application of Sense of Place in Public Participation in Planning Decision of the Renewal in Old Industrial Areas
}

Jiankun LOU, School of Architecture, Harbin Institute of Technology, Key Laboratory of Cold Region Urban and Rural Human Settlement Environment Science and Technology, Ministry of Industry and Information Technology, China

Wei DONG, School of Architecture, Harbin Institute of Technology, Key Laboratory of Cold Region Urban and Rural Human Settlement Environment Science and Technology, Ministry of Industry and Information Technology, China

Alin LIN, School of Civil Engineering and Architecture, Zhejiang Sci-tech University, China

\begin{abstract}
In the renewal of old industrial areas, residents' life has been affected. In order to explore the relationship between residents' sense of place and their attitude towards the future development direction, this study takes Xiangfang old industrial area as an example and conducts a field questionnaire survey. The calculation of Structural Equation Model shows that residents' sense of place can be divided into place attachment, place dependence and place identity in Xiangfang old industrial area, and the intensities are high. Moreover, the logistic regression shows that sense of place significantly impacts History and Environment preference. Place dependence and place attachment significantly impact History preference. And place identity is the only dimension that is significant to all types of preferences. These conclusions show the importance of a sense of place, especially place identity, in public participation. This study can help the urban renewal of Xiangfang old industrial zone and proves that sense of place can provide a way for the public to participate in planning decision-making and policy-making in the future.
\end{abstract}

\section{Keywords}

Sense of place, Public participation, Old industrial areas, Policy making, Structural Equation Model

\section{Introduction}

As China's urbanization has entered a new stage, the urban development model has gradually changed from incremental expansion to stock renewal. However, with the introduction of new industries and real estate development, there are usually land-use changes, demolition of old buildings, and occupation of green space in the renewal process. These changes have affected the lives of local residents to a great extent. Therefore, the opinions of local residents, the actual users of space, on the renewal scheme are particularly critical. In order to meet these challenges, public participation in planning and decisionmaking has become an important link in the process of urban renewal all over the world.

The place theory originated from the study of environmental psychology and perception in the 1950s. The concept of place refers to the geographical space composed of several spatial units occupied by people and things, which is the opposite of the concept of space. Geographer Yi-Fu Tuan believes that place comes into being, only when people give meaning to space, and he put forward the concept of 
sense of place in $1977^{[1]}$. Sense of place is a special emotional connection between people and place through long-term interaction ${ }^{[2,3]}$. It refers to people's feeling of place and a collection of place meanings.

Since the concept of sense of place was put forward, it has become a topic of concern in many disciplines and is considered one of the ten geographical thoughts that change the world. Since the concept was put forward, the research on sense of place has changed from phenomenological method to positivist research, and the research method has also changed from qualitative research to the combination of qualitative and quantitative research ${ }^{[4,5]}$. Although some researchers believe that sense of place is a onedimensional concept, most researchers believe that sense of place is a multi-dimensional concept ${ }^{[6-8]}$. However, there has been no consensus on the dimension for a long time. Jorgensen used the attitude structure model to divide the dimension of sense of place ${ }^{[9]}$. The three components of affection, cognition, and behavior in the attitude structure model correspond to place identity, place attachment and place dependence in environmental psychology. This study provides an easy to operate and reliable method for later researchers to measure people's attitudes towards the space environment. At present, much research has adopted this way of dividing the dimension of sense of place ${ }^{[10-13]}$. Recently, some research has taken the view that a critical multi-perspective should be encouraged to pay attention to sense of place in order to recognize the diversity of ways in which it is conceptualized and measured. This view holds that no research theory or plan can successfully participate in all aspects of people-place relationship investigation. Therefore, it may be challenging to have a universal way to divide its dimensions, and the intensity measures in specific empirical studies need to be statistically tested.

In recent years, the research on the people-place relationship in urban renewal areas has maintained a continuous growth trend. The relationship between sense of place, an important concept in the peopleplace relationship, and public participation has also been widely studied. Acedo found that sense of place is significant and positively correlated with civic engagement at the individual level ${ }^{[14,15]}$. Jorgensen asserted that a strong sense of place might be the reason why residents support policies ${ }^{[16]}$. Therefore, sense of place can play an essential role in predicting, guiding, and managing residents' emotional objects, behavior patterns, and supporting attitudes towards planning policies.Pánekt compared the differences in the views of different groups in the gentrified neighborhood on the future changes of the region with participatory mapping techniques through the influence of sense of place ${ }^{[17]}$. Erfani used sense of place as an investigative method to evaluate the process and outcomes of participatory urban redevelopment ${ }^{[18]}$. However, the research on what kind of urban development direction residents with a different sense of place prefer in public participation is still in the exploratory stage.

In the process of urban renewal, old industrial areas are usually the focus. With the cities' expansion, the industrial area initially located on the edge of cities has gradually become the central area of cities. Therefore, promoting the relocation and transformation of old industrial areas has become an effective way to improve the land-use efficiency of central urban areas, reasonably allocate land resources, and promote urban economic growth and quality improvement. In China's old industrial areas, most of the factory workers usually live around the factory. With the change of environment and acquaintance communication structure in the renewal process, residents' life has been greatly affected. Sense of place can help us understand this process and understand residents' expectations for future life and urban construction. Therefore, in order to further explore the relationship between residents' sense of place and their attitude towards the future development direction of old industrial areas, this study conducted a field questionnaire survey on sense of place and the recognition of the development direction of the old industrial area, to (1) test the dimension division of local residents' sense of place and calculate the intensity, (2) compare the influence of the intensity of different dimensions of sense of place on the preference of different development directions. 


\section{Methodology}

\subsection{Research area}

This study selects Harbin Xiangfang old industrial area as the research object, which is a famous old urban industrial area. Harbin, the capital of Heilongjiang Province, is located in northeast China. Its industrial system has developed since the city's establishment, and it has been an important industrial base in China until now. Xiangfang District is located in the southeast of Harbin. It is one of the earliest municipal districts and an essential area for the industrial development of Harbin. The types of industrial production in this area include textile, machinery, and boiler.

However, restricted by the development of enterprises and industrial transfer, traditional industries, especially heavy industries, began to decline gradually since entering the 21st century in China. The industrial economy of Xiangfang old industrial area, which was dominated by traditional manufacturing, had shrunk, and many enterprises in the district had suffered losses for a long time. In addition, most enterprises had no ability of self-transformation and self-development. National and local governments attached great importance to this phenomenon and promulgated various policies to constantly promote the renewal of old industrial areas. In February 2017, the Heilongjiang provincial government approved the implementation plan, Implementation Plan for Relocation and Reconstruction of Old Industrial area in Harbin City (2013-2020) (starting now referred to as the Implementation Plan), marking the official launch of a wide range of renewal projects in Xiangfang old industrial area. The Implementation Plan aims to eliminate backward production capacity through the relocation of existing enterprises, accelerate product upgrading, and process reengineering to drive the functional transformation and industrial upgrading of the whole city. At present, this initially prosperous industrial area is in the middle stage of urban renewal, slightly depressed.

The relocation area of Xiangfang old industrial area defined in the Implementation Plan is about 21 square kilometers, of which the start-up area is 7.47 square kilometers. The research scope is determined based on the scope of the relocation area. Moreover, the management scope of surrounding communities is considered. For communities whose jurisdiction covers the relocation area, their entire boundary is considered (Figure 1).

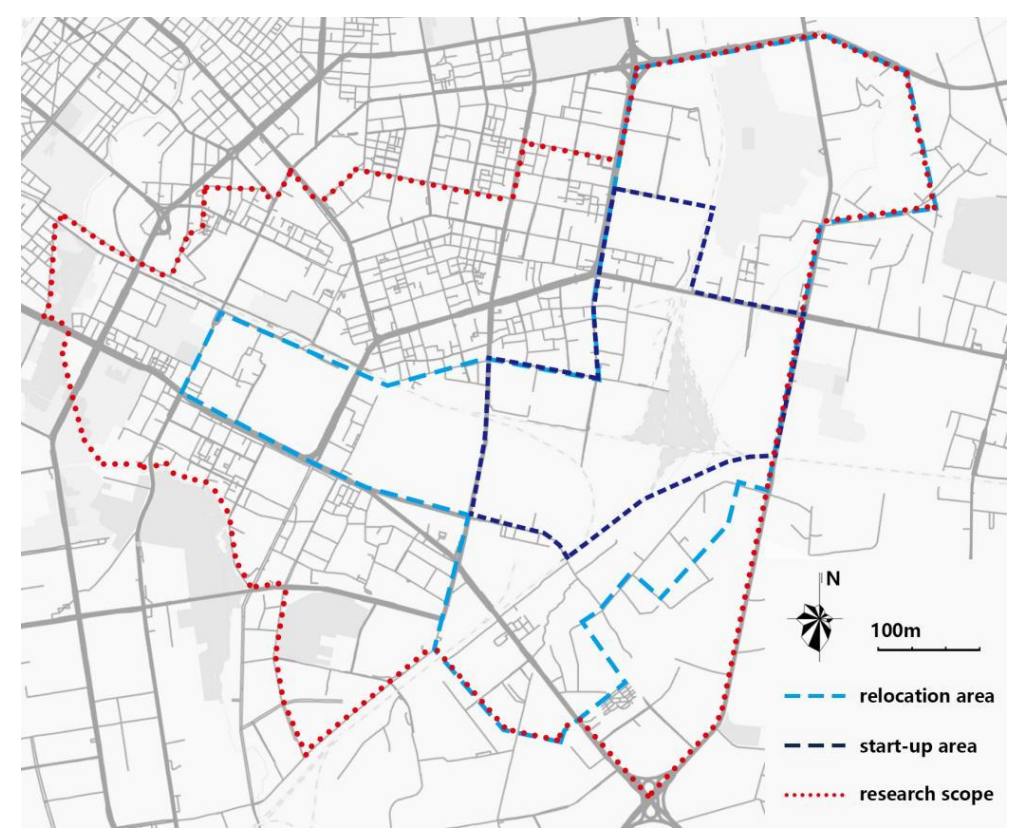

Figure 1. Editing the Headline. Source: Author. 


\subsection{Data collection}

The subjects of the survey are residents within the scope of the research. The survey adopted a questionnaire survey to collect data, and the questionnaire consisted of three parts. The first part of the questionnaire aims to measure residents' sense of place. Although there is no unified dimension division for sense of place in the related academic fields, place identity, place dependence, place attachment, and social bonding are the main dimensions related to the sense of place, which is widely agreed upon. The items of the questionnaire are based on the sense of place scale developed by Jorgensen in 2001. Totally, each dimension contains five descriptive sentences, which are translated into understandable Chinese. In the form of the Likert Scale, respondents are asked to choose according to the degree of agreement with the descriptions of sentences. A higher score means a higher agreement with the description of the sentences of residents. For example, 5 points represent "very agree," and 1 point represents "very disagree." All statement descriptions are positive.

The second part of the questionnaire aims to investigate residents' preferences for the future development direction of Xiangfang old industrial area. According to past research and empirical experience, the future renewal and development direction of old industrial areas can generally be summarized as: paying attention to industrial transformation and economic development, paying attention to social revitalization and community vitality, paying attention to historical protection and cultural heritage, and paying attention to environmental improvement and ecological protection. The questionnaire asks how much respondents agree with the importance of the above four directions, which are also divided into five levels. The last part of the questionnaire is the basic personal information, including gender, age, monthly income, residence years in Harbin and Xiangfang District, and annual residence time in Xiangfang District.

In order to make the sample more representative, the survey adopts the method of quota sampling, whose items are selected according to the predetermined characteristics of the group. In this survey, the gender and age characteristics of respondents are quota, and the data are based on the results of China's sixth population census. As people aged 24 and below have little understanding of the surrounding environment and weak ability to understand and answer the questionnaire, such people are not considered in the quota of samples. The quota sampling results for each gender and age group are shown in Table 1.

Table 1. Quota Sampling Results.

\begin{tabular}{|c|c|c|c|c|c|c|}
\hline & $\begin{array}{c}24 \text { Years Old } \\
\text { and Below }\end{array}$ & $\begin{array}{c}25-39 \\
\text { Years Old }\end{array}$ & $\begin{array}{c}40-54 \\
\text { Years Old }\end{array}$ & $\begin{array}{c}55-64 \\
\text { Years Old }\end{array}$ & $\begin{array}{c}65 \text { Years Old } \\
\text { and Over }\end{array}$ & Total \\
\hline Male & 10 & 51 & 55 & 22 & 14 & 152 \\
\hline Female & 10 & 47 & 51 & 24 & 16 & 148 \\
\hline Total & 20 & 98 & 106 & 46 & 30 & 300 \\
\hline
\end{tabular}

Shopping malls, parks, and other public activity places with a large flow of people in the research scope were selected as the survey sites (Figure 2). Questionnaires were filled in face-to-face and recycled onsite. The survey team composed of two trained graduate students distributed the questionnaire and informed the respondents of the purpose of the questionnaire before distribution. The data collection time was from November 2019 to January 2020 and from April to May 2020. A total of 300 questionnaires were distributed according to the quota, and all questionnaires were recovered and entered in time. After sorting, there were 252 valid questionnaires, and the effective rate was $84.0 \%$. 


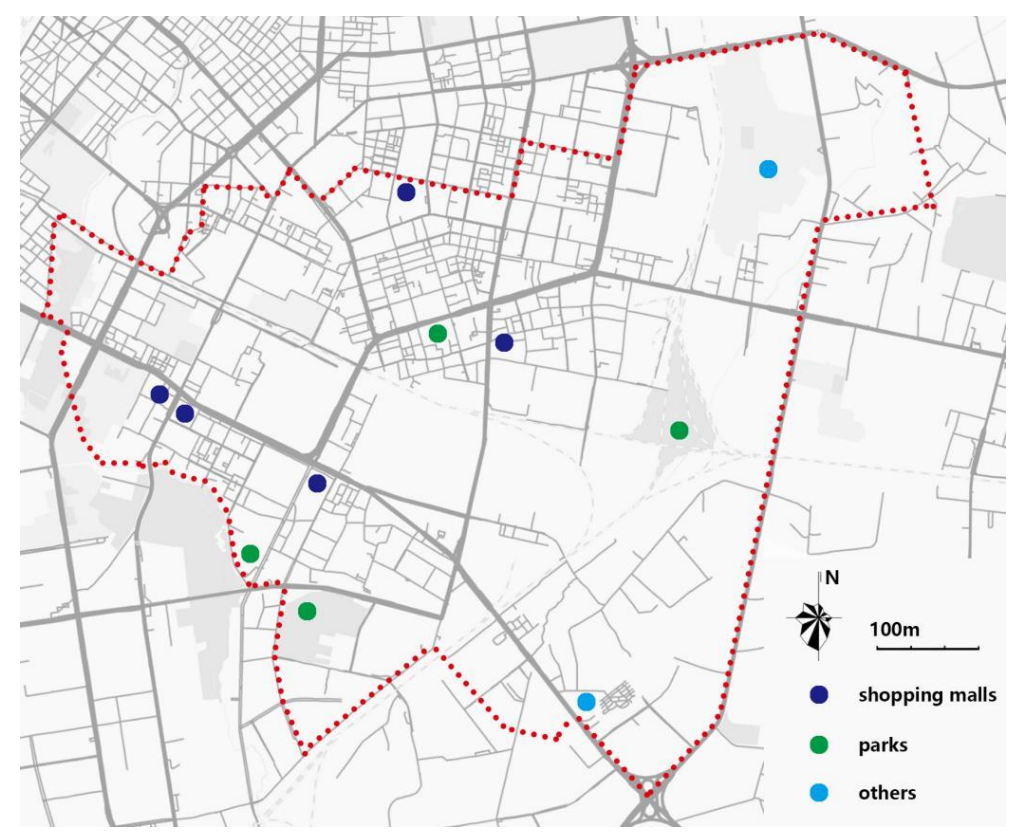

Figure 2. Survey Sites. Source: Author.

\subsection{Measurements}

Sense of place as a multi-dimensional concept has been agreed upon widely, but its specific dimensions are not unified, especially for residents in Chinese mainland cities. In order to fully understand the relationship between different dimensions, this study tests three model types and selected the model with the highest degree of fit with the measured data for subsequent analysis. Model 1 regards sense of place as the first-dimensional concept, with three dimensions of subordinate place identity, place dependence, and place attachment (Figure 3a). Model 2 regards sense of place and place attachment as the first dimensional concepts at the same level, with three dimensions of subordinate place identity, place dependence, and social bonding (Figure 3b). Model 3 regards sense of place as the firstdimensional concept, which includes four dimensions: place identity, place dependence, place attachment, and social bonding (Figure 3c).

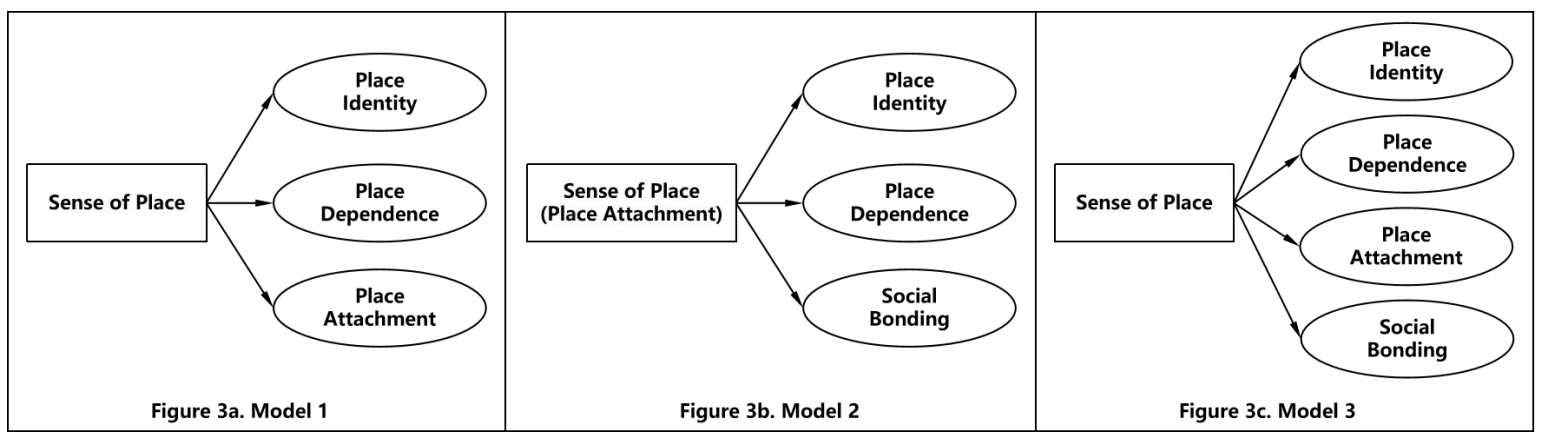

Figure 3. Three Model Types. Source: Author.

The measured data were substituted into the above theoretical model using Amos 23 , and then the sense of place model suitable for local residents in Xiangfang old industrial area is determined. Other data analysis contents of the study were completed by SPSS22. 


\section{Results}

\subsection{Sample characteristics}

The social-demographic characteristics, except for the gender and age of quota, are shown in Table 2. Most of the respondents' monthly income was between 2000-4000CNY, and this agreed with the average income of local residents. $76.6 \%$ of them were permanent residents (living in Xiangfang District for 9 months or more every year). On average, they had lived in Harbin for 29.9 years and in Xiangfang District for 21.6 years.

Table 2. Social-demographic characteristics.

\begin{tabular}{|c|c|c|c|c|c|c|c|}
\hline & & Number & Percentage & & & Number & Percentage \\
\hline \multirow{5}{*}{$\begin{array}{l}\text { Monthly } \\
\text { Income } \\
\text { (CNY) }\end{array}$} & $0-2000$ & 25 & $9.9 \%$ & \multirow{5}{*}{$\begin{array}{c}\text { Annual } \\
\text { Residence } \\
\text { Time }\end{array}$} & less than 1 month & 15 & $6.0 \%$ \\
\hline & $2000-4000$ & 81 & $32.1 \%$ & & 1-3 months & 8 & $3.2 \%$ \\
\hline & $4000-6000$ & 84 & $33.3 \%$ & & 3-6 months & 15 & $6.0 \%$ \\
\hline & $6000-8000$ & 34 & $13.5 \%$ & & 6-9 months & 21 & $8.3 \%$ \\
\hline & 8000 or more & 28 & $11.1 \%$ & & 9 months or more & 193 & $76.6 \%$ \\
\hline
\end{tabular}

\subsection{Structural Equation Model}

Structural Equation Model (SEM) is a statistical method based on a covariance matrix to analyze the relationship between variables ${ }^{[19]}$. It is widely used in psychology, economics, sociology, behavioral science, and other fields. Three models were built to examine the theoretically indicated hypotheses.

The three models all provided satisfactory goodness of fit to the sample data. As shown in Table 3 , all the values of Chi-square/df were small and satisfied the ideal critical criterion, so were the other fit indices ${ }^{[20]}$. After comparison, the fitting degree of Model I was the best, which showed that the theoretical model was most in line with the sense of place of residents in Xiangfang. The achieved fit statistics indicated a good basis to accept the proposed model to explain the relationship between sense of place and other dimensions. Therefore, this study selected Model I that was most consistent with the data, that was sense of place as the first-dimensional concept, with three dimensions of subordinate place identity, place dependence, and place attachment. Follow-up calculations were based on this model.

Table 3. Model fit indexes.

\begin{tabular}{|c|c|c|c|c|c|}
\hline Model Fit Index & Ideal Critical Criterion & Acceptable Value & Model 1 & Model 2 & Model 3 \\
\hline Chi-square/df & $1-3$ & $1-5$ & 1.90 & 2.76 & 2.44 \\
\hline RMSEA & $<0.08$ & $<0.09$ & 0.07 & 0.10 & 0.09 \\
\hline GFI & $>0.9$ & $>0.7$ & 0.91 & 0.84 & 0.84 \\
\hline AGFI & $>0.9$ & $>0.7$ & 0.88 & 0.80 & 0.79 \\
\hline CFI & $>0.9$ & $>0.7$ & 0.95 & 0.87 & 0.89 \\
\hline TLI & $>0.9$ & $>0.7$ & 0.94 & 0.84 & 0.87 \\
\hline
\end{tabular}

After the SEM test, the intensity of each dimension of residents' sense of place in Xiangfang District was calculated. The intensity scores of each dimension were expressed by the arithmetic mean of the scores 
of each question. The overall intensity score of sense of place was obtained by adding the arithmetic mean of the scores of the three dimensions. Therefore, the highest intensity score of each dimension was 5 points, and the highest overall intensity score of sense of place was 15 points. As shown in Table 4, the overall intensity score of residents' sense of place in Xiangfang District was 10.84 . The average intensity of residents' place identity was 3.63 . The average place dependence intensity was 3.55 . The average intensity of place attachment was 3.67 , which was the highest in all dimensions.

Table 4. Intensity scores of sense of place and the three dimensions.

\begin{tabular}{|c|c|c|c|c|}
\hline Dimension & Minimum & Maximum & Median & Average \\
\hline Sense of Place & 5.25 & 15.00 & 10.5 & 10.84 \\
\hline Place Identity & 2.00 & 5.00 & 3.60 & 3.63 \\
\hline Place Dependence & 1.80 & 5.00 & 3.60 & 3.67 \\
\hline Place Attachment & 1.00 & 5.00 & 3.75 & \\
\hline
\end{tabular}

On the level 5 Likert scale, a score of 3 indicates that the respondents are neutral. A score lower than 3 indicates a negative attitude, and a score higher than 3 indicates an approval attitude. After a single sample T-test, the average value of sense of place was compared with neutral attitude (9 points), and the average values of three dimensions were compared with neutral attitude ( 3 points). It was found that both were significant (Table 5).

Table 5. Results of single sample T-test.

\begin{tabular}{|c|c|c|c|}
\hline Dimension & T & Significance & Mean Difference \\
\hline Sense of Place & 13.97 & 0.000 & 1.84 \\
\hline Place Identity & 14.52 & 0.000 & 0.63 \\
\hline Place Dependence & 11.60 & 0.000 & 0.55 \\
\hline Place Attachment & 13.06 & 0.000 & 0.67 \\
\hline
\end{tabular}

\subsection{Preferences of development directions}

For simplicity, the following four development directions of the old industrial areas are referred to as Economy, Society, History, and Environment. The calculation results of residents' preferences for the directions are shown in Table 6. The results show that Environment was the highest preference in all directions while Economy and History were the lowest.

Table 6. Scores of preferences.

\begin{tabular}{|c|c|c|c|c|}
\hline Development Directions & Minimum & Maximum & Median & Average \\
\hline Economy & 1.00 & 5.00 & 4.00 & 4.08 \\
\hline Society & 2.00 & 5.00 & 4.00 & 4.19 \\
\hline History & 1.00 & 5.00 & 4.00 & 4.08 \\
\hline Environment & 3.00 & 5.00 & 5.00 & 4.54 \\
\hline
\end{tabular}


In order to further calculate the relationship between sense of place and preferences of development directions, this study analyzed the correlation between the above sense of place and three dimensions and four types of preferences, respectively. The calculation took the average value as the standard, and sense of place was transformed into a virtual variable, divided into a higher sense of place group and a lower sense of place group. Then, taking the lower sense of place group as a reference, the higher group and four types of preferences were analyzed by logistic regression. The other three dimensions did the same. The regression results are shown in Table 7.

Table 7. Results of logistic regressions.

\begin{tabular}{|c|c|c|c|c|c|c|}
\hline \multirow{2}{*}{ Model } & \multicolumn{2}{|c|}{$\begin{array}{l}\text { Unstandardized } \\
\text { Coefficients }\end{array}$} & \multirow{2}{*}{$\begin{array}{c}\text { Standardized } \\
\text { Coefficients } \\
\beta\end{array}$} & \multirow[t]{2}{*}{ R Square } & \multirow{2}{*}{$\begin{array}{l}\text { Adjusted } \\
\text { R Square }\end{array}$} & \multirow[t]{2}{*}{ Significance } \\
\hline & $\beta$ & Std.Error & & & & \\
\hline Sense of Place $\longrightarrow$ Economy & 0.136 & 0.114 & 0.075 & 0.006 & 0.002 & 0.233 \\
\hline Sense of Place $\longrightarrow$ Society & 0.068 & 0.097 & 0.045 & 0.002 & -0.002 & 0.481 \\
\hline Sense of Place $\longrightarrow$ History & 0.298 & 0.111 & 0.167 & 0.028 & 0.024 & 0.008 \\
\hline Sense of Place $\longrightarrow$ Environment & 0.256 & 0.080 & 0.198 & 0.039 & 0.035 & 0.002 \\
\hline Place Identity $\longrightarrow$ Economy & 0.387 & 0.112 & 0.213 & 0.045 & 0.042 & 0.001 \\
\hline Place Identity $\longrightarrow$ Society & 0.302 & 0.095 & 0.196 & 0.039 & 0.035 & 0.002 \\
\hline Place Identity $\longrightarrow>$ History & 0.449 & 0.109 & 0.251 & 0.063 & 0.059 & 0.000 \\
\hline Place Identity $\longrightarrow$ Environment & 0.384 & 0.079 & 0.295 & 0.087 & 0.084 & 0.000 \\
\hline Place Dependence $\longrightarrow>$ Economy & 0.176 & 0.114 & 0.097 & 0.009 & 0.006 & 0.123 \\
\hline Place Dependence $\rightarrow$ Society & 0.156 & 0.097 & 0.102 & 0.010 & 0.006 & 0.107 \\
\hline Place Dependence $\rightarrow$ History & 0.352 & 0.111 & 0.197 & 0.039 & 0.035 & 0.002 \\
\hline Place Dependence $\longrightarrow>$ Environment & 0.174 & 0.081 & 0.134 & 0.018 & 0.014 & 0.034 \\
\hline Place Attachment $\longrightarrow$ Economy & 0.000 & -0.004 & -0.007 & 0.114 & -0.004 & 0.953 \\
\hline Place Attachment $\longrightarrow>$ Society & 0.143 & 0.096 & 0.093 & 0.009 & 0.005 & 0.139 \\
\hline Place Attachment $\longrightarrow>$ History & 0.361 & 0.110 & 0.203 & 0.041 & 0.037 & 0.001 \\
\hline Place Attachment $\longrightarrow>$ Environment & 0.202 & 0.081 & 0.156 & 0.024 & 0.020 & 0.013 \\
\hline
\end{tabular}

The results show that for History preference, sense of place was significant at the $90 \%$ confidence level, while for Environment preference, it was significant at the $95 \%$ confidence level. Place identity was the only dimension that was significant to all types of preferences. For Economy and Society preferences, it was significant at the $99 \%$ confidence level, and for History and Environment preferences, it was significant at the $99 \%$ confidence level. Place dependence and place attachment both reached the $95 \%$ significant confidence level for History preference. All the above effects were positive, and place identity had the most significant impact on Environment, whose Adjusted R Square is 0.084 . 


\section{Discussion}

\subsection{Sense of place in Xiangfang old industrial areas}

Sense of place of residents in Xiangfang old industrial area most agrees with the theory of attitude structure model, which can provide a reference for future research. At the same time, the overall intensity of sense of place in Xiangfang and the intensity of place identity, place dependence, and place attachment are relatively high. This proves that permanent residents have deep feelings for their place of residence $^{[21]}$. Many of studies have shown that time will probably increase the interaction between people and places and then improve their relationship.

Place attachment refers to a positive connection between people and the environment ${ }^{[22]}$. It corresponds to the affection dimension in the attribute structure model. The intensity of this dimension is the highest, which may indicate that compared with role identity (place identity) and functional dependence (place dependence), the residents of Xiangfang old industrial area have more profound emotions for the place. They tend to stay in this place and reach a psychological state of comfort and safety.

\subsection{Development directions and sense of place}

According to the results, people with higher intensity have a significantly higher preference for History than people with lower intensity in all dimensions. History represents the residents' view that Xiangfang old industrial area should pay attention to historical protection and cultural heritage in the future. This shows that people with closer links to the place will pay more attention to preserving and developing local history and cultural traditions. In urban renewal, the original traces are constantly being erased with the demolition of buildings and the flow of population. However, people who care here usually miss and regret these. Therefore, in the current and future urban renewal, the government should pay more attention to humanistic care and retain local memories.

Place identity is regarded as a substructure of self-identity, which is generally defined as individuals or groups define themselves as members of a specific place to construct their position and role in society through the place ${ }^{[23]}$. In this study, people with higher intensity of place identity more agree with all directions conducive to the development of Xiangfang old industrial area. This shows that people with high place identity are more concerned about local development and have a more urgent need for a better place. People with high place identity are also more likely to contribute to future regional development and may have higher enthusiasm to participate in the planning decision. Therefore, in the process of public participation, the government can ask more about and adopt the suggestions of these people.

Otherwise, people with higher intensity of sense of place also have a significantly higher preference for Environment than people with lower intensity. Environment represents the residents' view that Xiangfang old industrial area should pay attention to environmental improvement and ecological protection. This may be because people with a stronger sense of place pay more attention to the comfort of living locally. The natural environment is more closely related to daily life, especially for the residents of old industrial areas, which has been built for a long time and caused more pollution by industrial production. Therefore, the government should take environmental governance as an essential goal of future development in the process of transformation.

\subsection{Limitation and future research}

Firstly, personal factors are a kind of factor that has a significant impact on sense of place, but they are not discussed in this study. Future research can focus on whether there are differences in sense of place among different groups. In addition, this study is aimed at the whole old industrial area. In future 
planning practice, we should explore which specific places affect sense of place to carry out targeted planning decisions ${ }^{[24]}$.

\section{Conclusion}

This study takes Xiangfang old industrial area as an example and conducts a field questionnaire survey on the local residents' sense of place and their recognition of the development direction of the old industrial areas. The relationship between the sense of place and their preference for the future development direction of the urban renewal area is explored. The results show that the residents' sense of place can be divided into place attachment, place dependence and place identity and the overall intensities are high. Moreover, sense of place significantly impacts History and Environment preference. Place dependence and place attachment significantly impact History preference. And place identity is significant to all types of preferences. These show that the difference in the dimension of sense of place indeed leads to different opinions of residents on the future development direction, which may affect public participation in policy-making.

These research results can help the urban renewal of Xiangfang old industrial area and provide a reference for other similar areas. More importantly, this study proves that sense of place can be used as an aspect of the residents' survey, which provides a way for the public to participate in planning decisionmaking in the future. The government and other policymakers can take the sense of place as an essential basis so that urban construction can better meet the wishes of local residents in the future public participation in planning practice.

Funding: This research is supported by The National Natural Science Foundation of China (中国国家自然 科学基金项目 No. 51878204). And it is also the research achievement of Zhejiang Federation of Humanities and Social Sciences (浙江省社会科学界联合会研究课题成果 No. 2022N29).

Acknowledgments: Specifically, we thank our teammates for their valuable help with data collection and analysis.

\section{References}

[1] Tuan Y. (1977) Space and place : the perspective of experience. Minneapolis: University of Minnesota Press.

[2] Shamai S. (1991) 'Sense of place: An empirical measurement', Geoforum, 22(3), p347-358.

[3] Nelson J, Ahn J, Corley E. (2020) 'Sense of place: Trends from the literature', Journal of urbanism, 13(2), p236-261.

[4] Williams D, Roggenbuck J. (1989) 'Measuring place attachment: Some preliminary results'. Paper Presented at the Session on Outdoor Planning and Management NRPA Symposium on Leisure Research, San Antonio, Texas.

[5] Stedman R. (2003) 'Sense of place and forest science toward a program of quantitative research', Forest Science, 49(6), p822-829.

[6] Jorgensen B, Stedman R. (2006) 'A comparative analysis of predictors of sense of place dimensions: Attachment to, dependence on, and identification with lakeshore properties', Journal of Environmental Management, 79(3), p316-327.

[7] Brown G, Raymond C M, Corcoran J. (2015) 'Mapping and measuring place attachment', Applied Geography, 57, p42-53. 
[8] Soini K, Vaaral H, Poutaa E. (2012) 'Residents' sense of place and landscape perceptions at the ruralurban interface', Landscape and Urban Planning, 104(1), p124-134.

[9] Jorgensen B, Stedman R. (2001) 'Sense of Place as an Attitude: Lakeshore owners attitudes toward their properties', Journal of Environmental Psychology, 21(3), p233-248.

[10] Jorgensen B, Stedman R. (2011) 'Measuring the spatial component of sense of place: A methodology for research on the spatial dynamics of psychological experiences of places', Environment and planning. B, Planning \& design, 38(5), p795-813.

[11] McCunn L, Gifford R. (2018) 'Spatial navigation and place imageability in sense of place', Cities, 74, p208-218.

[12] Žlender V, Gemin S. (2020) 'Testing urban dwellers' sense of place towards leisure and recreational peri-urban green open spaces in two European cities', Cities, 98(102579), p1-12.

[13] Wang Z, Li D, Cheng H, Luo T. (2020) 'Multifaceted influences of urbanization on sense of place in the rural-urban fringes of China growing, dissolving, and transitioning', Urban Planning and Development, 146(1: 04019026), p1-12.

[14] Acedo A, Painho M, Casteleyn S. (2017) 'Place and city: Operationalizing sense of place and social capital in the urban context', Transactions in GIS, 21(3), p503-520.

[15] Acedo A, Oliveira T, Naranjo-Zolotov M, Painho M. (2019) 'Place and city: Toward a geography of engagement', Heliyon, 5(8: e2261), p1-14.

[16] Jorgensen B, Stedman R. (2006) 'A comparative analysis of predictors of sense of place dimensions: Attachment to, dependence on, and identification with lakeshore properties', Journal of Environmental Management, 79(3), p316-327.

[17 ]Pánek J, Glass M, Marek L. (2020) 'Evaluating a gentrifying neighborhood's changing sense of place using participatory mapping', Cities, 102(102723), p1-12.

[18] Erfani G. (2020) 'Sense of place as an investigative method for the evaluation of participatory urban redevelopment', Cities, 99(102648), p1-12.

[19] Golob T. (2003) 'Structural equation modeling for travel behavior research', Transportation Research Part B: Methodological, 37(1), p1-25.

[20] Hu L, Bentler P. (1999) 'Cutoff criteria for fit indexes in covariance structure analysis: Conventional criteria versus new alternatives', Structural Equation Modeling: A Multidisciplinary Journal, 6(1), p1-55.

[21] Williams A, Kitchen P, DeMiglio L, Eyles J, Newbold B, Streiner D. (2010) 'Sense of place in Hamilton, Ontario: Empirical results of a neighborhood-based survey', Urban Geography, 31(7), p905-931.

[22] Lewicka M. (2011) 'Place attachment: How far have we come in the last 40 years?', Journal of Environmental Psychology, 31(3), p207-230.

[23] Peng J, Strijker D, Wu Q. (2020) ‘Place identity: How far have we come in exploring its meanings?', Frontiers in Psychology, 11(294), p1-19.

[24] Raymond C, Kytta M, Stedman R. (2017) 'Sense of place, fast and slow: The potential contributions of affordance theory to sense of place' Frontiers in Psychology, 8(1674), p1-14. 